\title{
PROPOSTA DE INDICADORES DE SMART CITY SUSTENTÁVEL
}

\section{JOÃO VITOR SOUZA TEIXEIRA | UFMG \\ RENATA MARIA ABRANTES BARACHO PORTO | UFMG}

\section{INTRODUÇÃO}

Os centros urbanos e urbanizados estão recebendo cada vez mais pessoas advindas das áreas rurais. Se as previsões da ONU se concretizarem, até 2050, 70\% da população pode viver nessas áreas (1). Essa migração desordenada pode causar vários impactos socioeconômicos e ambientais, como poluição do ar, solo e água, exaustão de recursos naturais, trânsito e etc. $(2,3)$. Para conter esses problemas, as cidades devem investir em Tecnologias de Informação e Comunicação (TICs), ferramenta fundamental no conceito de uma Smart City.

O termo Smart surgiu com o advento dos Smart Phones, dispositivos celulares capazes de interagir com a internet e fazer uso de aplicativos das mais diversas funcionalidades. À medida que a tecnologia evoluiu, os celulares passaram a se conectar também com carros, televisões, aparelhos de som e outros, garantindo às pessoas a possibilidade de viverem uma Smart Life. Não obstante, os edifícios também evoluíram de forma inteligente, lançando mão de ferramentas como controle de consumo de água e energia inteligente, uso de energias renováveis e centrais de processamento e leitura de dados, por exemplo, o que os tornou Smart Buildings (4). A junção de todos esses dispositivos criou as chamadas Smart Cities ou Cidades Inteligentes.

Não há um consenso geral para o conceito de Smart City, sendo que vários especialistas da área escreveram a respeito delas trazendo suas próprias visões do que devem conter. O que a maioria tem em comum, porém, é o fato da utilização das TICs e o objetivo principal de que as Smart Cities devem prezar pela qualidade de vida dos seus cidadãos (5).

Algumas cidades, porém, evoluíram tanto em tecnologia que acabaram por perder qualidade de vida, aumentando exponencialmente seus valores de $\mathrm{m}^{2}$, reduzindo a necessidade dos moradores de transitarem pela mesma e se tornando verdadeis "cidades fantasmas", como foi o caso de Masdar, nos Emirados Árabes $(2,3)$. Surge então a grande problemática de como garantir que uma Cidade Inteligente seja, ao mesmo tempo, tecnológica e que garanta o aumento da qualidade de vida de seus usuários e cidadãos.

\section{PROPOSTA DE INDICADORES}

Visando sanar este problema, o presente estudo traz uma proposta de indicadores para as Cidades Inteligentes, focando na qualidade de vida como principal premissa. Para cria-lo, foram analisados cinco indicadores, sendo eles três de Cidades Inteligentes (Cohen, Giffinger e Alexopoulos), um de Sustentabilidade (ISO 37120:2014) e um de Qualidade de Vida Urbana. Eles foram separados em temas e à medida que esses temas eram recorrentes nos modelos os mesmos eram hierarquizados em prioridades. Para criar um sistema de pesos e customização, será aplicado um questionário baseado no Modelo de Delphi Modificado, reunindo cerca de 30 especialistas. O questionário servirá ainda para criar um forecast de cenários preditivos para as Cidades Inteligentes de 3, 5 e 10 anos.

\section{REFERÊNCIAS}

ORGANIZAÇÃO DAS NAÇÕES UNIDAS. ONU: Mais de $70 \%$ da população mundial viverá nas cidades até 2050. [2013]. Disponível em: <https://nacoesunidas. org/onu-mais-de-70-da-populacao-mundial-vivera-em-cidades-ate-2050/> Acesso em: 03 de fevereiro de 2020.

FIGUEIREDO, Gabriel Mazzola Poli de, O Discurso e a Prática de Smart City: Perspectivas críticas e aproximações sistemáticas no contexto de metrópoles latino-americanas. 2018, 80f., Dissertação (Mestrado em Arquitetura e Urbanismo) - Faculdade de Arquitetura e Urbanismo, Universidade de São Paulo, São Paulo, 2018.

TEIXEIRA, João Vitor Souza, Proposta de Indicadores para Smart City Sustentável. In: SEMINÁRIO DE PESQUISA EM PÓS-GRADUAÇÃO E INOVAÇÃO, 5., 
2021, Belo Horizonte, Futuros Possíveis, 2021, p. 46-64.

BARACHO, Renata Maria Abrantes, et.al., A Proposal for Developing a Comprehensive Ontology for Smart Cities/Smart Buildings/Smart Life. Disponível em: https://www.researchgate.net/publication/332028167 Acesso em: 04 de fev, 2020.

NEIROTTI, Paolo et. al., Current trends in Smart City initiatives: Some stylised facts. Cities: The International Journal of Urban Policy and Planning, Torino, 2014, p.25-36. 